\title{
A interferência da estrutura produtiva contemporânea na saúde do trabalhador
}

Recebido: 28 jan 2019 Aceito: 10 fev 2019

Autor de correspondência: hcanella@gmail.com

Conflito de interesses: Os autores declaram não haver nenhum interesse profissional ou pessoal que possa gerar conflito de interesses em relação a este manuscrito.

\section{Resumo}

O processo saúde-doença não deve ser reduzido ao aspecto individual e biológico. Sua essência está em reconhecer seu caráter social e sua determinação histórica. Neste sentido, o impasse na relação trabalho e saúde, ao longo dos anos, encontram-se nas diferentes formas assumidas pela exploração do trabalho. Dela, por interesse do capitalista, surgem novas e melhores formas de extração do excedente, por meio da otimização de sua produtividade. A crítica a este movimento está na forma desbalanceada pela qual se estabelece, favorecendo os interesses do capital em detrimento do bem-estar dos trabalhadores, intensificando a degradação do trabalho devido ao inerente distanciamento da produção às necessidades sociais, estando a primeira voltada para a desmedida reprodução do valor. Ademais, o neoliberalismo, como modelo vigente do capitalismo, prioriza os interesses do capital financeiro, que não necessita do trabalhador (diferente do capital produtivo), uma vez que produz riqueza a partir do próprio dinheiro. Neste contexto, embora tenham ocorrido avanços na conquista de direitos sociais e trabalhistas nas últimas décadas, o trabalho manteve-se como fonte inesgotável de diferentes formas de sofrimento e adoecimento. A adaptação do processo de trabalho às novas condições de controle dos meios de produção e de reprodução do capital foram traduzidas pelo mercado como flexibilização. Este movimento favoreceu a disseminação de novas formas de trabalho, como o temporário, doméstico, tele trabalho, a terceirização da produção para espaços que permitem maior exploração da mão de obra, a redução dos empregos estáveis e o aumento de postos informais. O resultado dessa equação é o aumento da massa de desempregados (exército industrial de reserva) que não consegue se inserir no mercado ou recorre aos trabalhos precários e ao subemprego. A precarização do trabalho, resultado da reestruturação produtiva e organizacional adotada por empresas para aumentar seus lucros, bem como o desemprego crescente, associados à perda dos direitos e baixos salários, constituem um cenário que afeta tanto empregados inseridos no mercado formal, quanto àqueles excluídos e em segmentos mais vulneráveis do mercado informal, os expondo aos mais variados riscos. A classe trabalhadora convive com incertezas e inseguranças crônicas, sendo cada vez mais exigida em termos de qualificação e produtividade. Por mais que existam diretrizes definidas por órgãos como a Rede Nacional de Atenção Integral à Saúde do Trabalhador RENAST e Centros de Referência em Saúde do Trabalhador - CEREST, bem como 
a própria Lei Orgânica da Saúde e os avanços com a finalidade de articular ações assistenciais, vigilância, prevenção e promoção, se distanciando da abordagem exclusivamente dos aspectos biológicos, a saúde do trabalhador muitas vezes está restrita às iniciativas das próprias empresas (através de seu Serviço Especializado em Engenharia de Segurança e em Medicina do Trabalho - SESMT) que, por sua vez, estão mais preocupadas em evitar processos trabalhistas do que com o bem-estar de seus colaboradores. Segundo o Ministério Público do Trabalho, foram gastos em torno de $\mathrm{R} \$ 22$ bilhões com benefícios acidentários decorrentes de acidentes e doenças ocupacionais desde 2012. O número corresponde a cerca de 280 milhões de dias de trabalho perdidos por indivíduos incapacitados para exercer suas funções. Outro dado impressionante é o número de acidentes de trabalhado a cada ano: 700 mil; o quarto pior do mundo, estando somente atrás da China, Índia e Indonésia. A estrutura contemporânea do trabalho impõe graves consequências individuais e sociais, não apenas em nível do consumo e qualidade de vida, mas também na perspectiva de futuro. Fica claro que o bem-estar do trabalhador não é um fator determinante para que se redefinam os parâmetros das relações trabalhistas e do modo de produção. A partir do momento em que o próprio capital é meio e fim para a geração de lucro, a mão de obra se torna dispensável e/ou de fácil reposição. A proposta deste estudo é realizar levantamento sobre o que a literatura cientifica apresenta acerca da imposição da organização contemporânea do processo de Trabalho sobre a saúde do trabalhador, sob perspectiva da tendência de precarização do trabalho e desemprego crescentes. Objetivo: pretende-se demonstrar as principais transformações do Processo de Trabalho na sociedade capitalista, afim de verificar se os esforços para Promoção e Prevenção da Saúde do Trabalhador têm acompanhado suas alterações. Método: essa revisão sistemática, do tipo metassíntese, sobre o tema Saúde do Trabalhador foi estabelecida a partir da definição de pergunta de pesquisa para nortear suas atividades subsequentes: Em que peso a organização contemporânea do processo de trabalho interfere na saúde do trabalhador? Em seguida, foi realizada busca por Descritores em Ciências da Saúde - DeCS que melhor abrangessem a indagação proposta. Os termos e descritores aderentes ao tema pesquisado foram diversos (Saúde do Trabalhador; Condições de Trabalho; Doenças Profissionais; Equilíbrio Trabalho Vida; etc.) e, sobre eles, foi aplicada técnica de busca com os delimitadores $A N D$ e $O R$, a fim de filtrar os resultados obtidos, possibilitando trabalhar sobre uma base restrita de artigos coerentes com o tema. Neste sentido, para a construção da sintaxe de pesquisa, os descritores foram separados entre População, Contexto e Fenômeno. Foi definido que a população é a própria saúde do trabalhador, sujeita aos condicionamentos estabelecidos pelas variáveis do contexto: condições, ambiente e mercado de trabalho, bem como a vigilância em saúde do trabalhador e suas relações trabalhistas. Vale destacar que o conceito de saúde no descritor Saúde do Trabalhador não se restringe a ausência de doença. Como sua própria definição sugere, trata-se da promoção e manutenção do bem-estar físico, mental e social dos trabalhadores em todas as ocupações, 
bem como a prevenção e proteção dos trabalhadores dos riscos resultantes de fatores adversos à saúde. Por fim, foi entendido como Fenômeno, o adoecimento do trabalhador, representado aqui pelo descritor Doenças Profissionais. Vale destacar que diferentes sintaxes contemplando as variáveis do estudo foram testadas nas bases de artigos e, ao final dos testes, se propôs utilizar na base de dados Lilacs a Sintaxe: Saúde do Trabalhador [Descritor de assunto] and Ambiente de Trabalho $O R$ Condições de Trabalho $O R$ Mercado de Trabalho $O R$ Vigilância em Saúde do Trabalhador $O R$ Relações Trabalhistas $O R$ Equilíbrio Trabalho-Vida [Descritor de assunto] and Doenças Profissionais [Descritor de assunto], obtendo como resultado 84 estudos, sobre os quais serão realizadas as análises propostas.

Descritores: Saúde do Trabalhador; Condições de Trabalho; Ambiente de Trabalho; Mercado de Trabalho; Vigilância em Saúde do Trabalhador; Relações Trabalhistas; Doenças Profissionais. 